\title{
Childhood trauma: methods for the identification of physeal fractures in non- adult skeletal remains
}

Article

Accepted Version

Verlinden, P. and Lewis, M. E. (2015) Childhood trauma: methods for the identification of physeal fractures in non-adult skeletal remains. American Journal of Physical Anthropology, 157 (3). pp. 411-420. ISSN 0002-9483 doi:

https://doi.org/10.1002/ajpa.22732 Available at https://centaur.reading.ac.uk/51459/

It is advisable to refer to the publisher's version if you intend to cite from the work. See Guidance on citing.

To link to this article DOI: http://dx.doi.org/10.1002/ajpa.22732

Publisher: Wiley

All outputs in CentAUR are protected by Intellectual Property Rights law, including copyright law. Copyright and IPR is retained by the creators or other copyright holders. Terms and conditions for use of this material are defined in the End User Agreement.

www.reading.ac.uk/centaur 
Central Archive at the University of Reading

Reading's research outputs online 


\title{
Childhood trauma: Methods for the identification of physeal fractures in non-adult skeletal remains
}

\author{
Verlinden, $\mathrm{P}$ and Lewis, ME \\ University of Reading \\ Reading, \\ RG6 6AB
}

Number of pages: 20, with 7 figures, 4 tables and 1 chart.

Abbreviated title: Identifying physeal fractures

Key words: non-adults, trauma, growth plate, falls, birth injury

Petra Verlinden

302 Gosbrook road

RG4 8EB

Caversham, Reading

United Kingdom

Tel. +44 7564054948

Verlinden.petra@gmail.com

Funded by a Leverhulme Trust Studentship (2011-14).

\section{ABSTRACT \\ Objectives}

Today, fractures at the growth plate (or physis) are common injuries in children, but provide challenges of identification in skeletonized remains. Clinical studies provide detailed information on the mechanisms, locations, age of occurrence, and complications associated with physeal fractures, enabling the development of new criteria for identifying this injury in non-adults. To test these criteria, skeletal remains from five rural and urban medieval cemeteries were examined.

\section{Methods}

The sample consisted of 961 skeletons (0-17 years) with open epiphyses. Macroscopic observation looked for any irregularities of the metaphysis or epiphysis which was consistent with the clinical appearance of physeal fractures or resulting complications. Radiographic examination was applied to identify fracture lines or early growth arrest.

\section{Results}

This study revealed 12 cases of physeal trauma (1.2\%). Physeal fractures occurred predominantly at the distal end (75\%), and while they were identified in all age categories, they were most frequent in those aged $12-17$ years $(0.2 \%$ TPR $)$. The humerus was the most commonly affected location $(3 / 12$ or $25 \%)$.

\section{Conclusions}

This study highlights the potential for recognizing physeal fractures in children of all ages, enhancing our understanding of non-adult trauma, and enabling us to assign a more precise age of the injury to build up a picture of their activities in the past. 
The study of antemortem trauma in non-adult skeletal remains is challenging. Changes such as plastic deformity are subtle, and common fracture types include greenstick and buckle fractures, which heal quickly and without deformity. New bone deposits and raised areas that signal callus formation can mimic other conditions such as infections, and any bowing may be mistaken for that seen in vitamin D deficiency (Lewis 2014). Due to these limitations, reports of non-adult trauma are rare, even in articles dedicated to their study (Jimenez-Brobeil et al. 2007; Djuric et al. 2010). Recent research has highlighted the potential for identifying perimortem injuries (Gaither and Murphy 2012) and cranial trauma in children (Fibiger 2013), but childhood injuries are most often studied indirectly through deformities in adults showing growth arrest and shortening of the affected limb (Dawes and Magilton 1980; Glencross and Stuart-Macadam 2000; Glencross and Stuart-Macadam 2001; Mays et al. 2007; Waldron and Rodwell 2007; Glencross 2011).

The growing child is especially susceptible to fractures at the growth plate, situated between the metaphysis and epiphysis (Caine et al. 2006). Physeal injuries are used here to refer to all trauma at the growth plate and surrounding bone, including the epiphyses and apophyses. As the growth plate consists of soft tissue, damage needs to be examined indirectly by identifying subtle changes to the dry bone that may only exist for a short period of time after the trauma, that is to say, on the non-adult skeleton.

\section{Clinical features of physeal fractures}

The most widely used classification for physeal fractures was developed by Salter and Harris in 1963. Type I Salter-Harris fractures, most common in the distal fibula, describe the separation of the epiphysis from the metaphysis along with the germinal layer of the growth plate (Eastwood and de Geldere 2011) (Fig. 1a). While a type II Salter-Harris fracture, often seen in hand phalanges and distal radius (Peterson et al. 1994; Cannata et al. 2003), refers to the separation of the epiphysis together with a triangular bone fragment of the metaphysis, which remains attached to the periosteum. Type II is the most common Salter-Harris fracture (Peterson et al. 1994; Eastwood and de Geldere 2011).

When the fracture line crosses the physis, this is known as either a type III or IV Salter-Harris fracture. A type III Salter-Harris fracture consists of a fracture line running along the plane of the physis before abruptly angulating about 90 degrees to pass through the epiphysis and exit at the joint surface. One fragment of epiphysis will remain attached to the metaphysis, while the other fragment will be separated from the metaphysis along with part of the germinal layer (Fig. 1d). In case of a type IV Salter-Harris fracture, the fracture line crosses the metaphysis, physis, and epiphysis in an oblique line, which leads to the separation of a large triangular fragment (Ogden 2000; Eastwood and de Geldere 2011) (Fig. 1e). Frequently affected locations are the hand phalanges and distal tibia (Salter-Harris III) and distal tibia and distal humerus (Salter-Harris IV).

Officially a fifth Salter-Harris fracture type exists. It describes a situation in which the entire growth plate is destroyed by a severe crushing injury. However, doubts have been expressed over the actual existence of this fracture type as it concerns a potential secondary consequence of any physeal fracture, rather than an actual fracture type (Peterson et al. 1994). It is doubtful that this lesion would be identifiable on dry bone and hence this fracture type was not considered in this study. (Peterson et al. 1994).

Common complications are determined by the amount of displacement of the epiphysis and may provide the opportunity for the injury to be identified osteologically. Salter-Harris I and II fractures are usually closed but complications can arise due to damage to the periosteum (Fig 2.). The periosteum remains attached to the epiphysis, but may be stripped from the metaphyseal surface on the side of compression, leading to localized subperiosteal new bone formation (SNBF) (Brashear 1959) (Fig. 2a). On the side of tension, 
the periosteum may be torn and trapped between the fragmented layers of the growth plate, leading to localized growth arrest after reduction (Gruber et al. 2002). Such peripheral growth arrest will lead to anchoring of the physis and joint misalignment due to uneven growth (Ecklund and Jaramillo 2002) (Fig. 2b). Today, reduction of the displaced epiphysis can occur spontaneously. If the displaced fragment remains this may lead to a permanent angulation of the joint (Ogden 2000). However, in a child with enough growth remaining such angulations can remodel entirely over time (Peterson 2007) (Fig. 2c).

In Salter-Harris III or IV fractures, the metaphyseal or epiphyseal fragments are usually unstable elements which need surgery (pinning) for the injury to heal completely. Salter-Harris IV fractures at the distal humerus occasionally lead to non-union after a displaced fragment is left uncorrected (Flynn and Richards 1971; Hardacre et al. 1971). This will lead to an unstable elbow, asymmetrical growth and a progressive valgus deformity (Flynn et al. 1975). A Salter-Harris IV fracture can be open, potentially leading to secondary infection. Infection can also complicate fracture blisters which occasionally form at the ankle after a complicated Salter-Harris fracture (Ogden 2000). Physeal fractures which cross the growth plate are more frequently associated with growth arrest due to extensive cellular disorganisation (Rathjen and Birch 2006). The size and area of growth arrest is determined by fracture location (Ecklund and Jaramillo 2002). In the distal femur, the central undulation of the growth plate has led to a predisposition to central growth arrest (Ecklund and Jaramillo 2002). Similarly, growth arrest frequently occurs in the anterior-medial portion of the distal tibial growth plate, causing peripheral growth arrest (Ecklund and Jaramillo 2002).

In a study of 2650 long bone fractures in modern children, 30\% consisted of physeal fractures (Mann and Rajmaira 1990), while in a Minnesota study of 951 physeal fractures, fractures of the hand phalanges accounted for around 37\% of cases (Peterson et al. 1994). The occurrence of physeal fractures shows a small but steady increase during early childhood, with peaks between the ages of 9 and 16 years (Peterson et al. 1994). The one exception to this is the distal humerus, where an earlier peak in occurrence has been observed at 4-8 years, perhaps due to the complexity of the distal humeral growth plate at an earlier age (Peterson and Peterson 1972; Peterson et al. 1994).

The location and outcome of fractures can vary and these factors need to be taken into account when assessing prevalence rates in the past. For example, physeal fractures at the distal femur are uncommon with Peterson and colleagues reporting an incidence of just $1.4 \%$ (13/951 cases), but these fractures are often accompanied by complications (Basener et al. 2009) (Table 1), whereas the more common fractures of the hand phalanges rarely result in

Table 1 deformities that we may observe in the osteological context.

The underlying causes of physeal fractures today are likely to differ substantially from those in the past. While falls may have occurred in all time periods, and caused $19 \%$ of physeal injuries across the age groups in the Minnesota study, other frequent causes, such as sports/recreation and motor-vehicle accidents which made up $61 \%$ of the Minnesota injuries, would not have been as common in the past (Peterson et al. 1994). Understanding the cause of the injury in a specific location is also important. Tibial injuries were the third most common type in Minnesota but are usually associated with high-velocity accidents, although they can occur in falls (Leary et al. 2009).

The aim of this study was to create new diagnostic criteria to identify growth plate injuries in non-adult skeletal remains. These criteria were then applied to a large series of non-adult skeletons from medieval England in order to ascertain prevalence and skeletal distribution of this injury, as well as evaluating the health risks to children in the past affected by this type of trauma.

\section{MATERIALS}


Table 2

Non-adult individuals (0-17 years) from five early and later medieval sites (AD 9001600) in England were assessed macroscopically and radiographically for the presence of physeal fractures (Table 2). Due to the size of the London St Mary Spital collection, a random sample of well-preserved individuals were selected with around 100 individuals for each age group (0-5 years; 6-11 years and 12-17 years) (Centre for Human Bioarchaeology 2013a; b; c; d).

This sample comprised non-adults from both urban and rural sites, covering a time period of around 700 years. Samples from Raunds Furnells, Northamptonshire and St. Oswald's Priory, Gloucester represent populations involved in agricultural production and trading of goods with nearby towns (Heighway and West 1980; Boddington 1996; Baker and Holt 2004; Audouy and Chapman 2009; Stamper 2009; Lewis 2013). Agriculture was also a major occupation in Barton-upon-Humber, Lincolnshire although small scale industry and trade is suggested through the presence of a market and two mills (Bryant 2003). The St. Mary Spital cemetery in London represents a population from a more urbanized environment. Some of the older children may have been migrants to the city with the purpose of becoming apprentices or servants (Hanawalt 1986; Goldberg 2006; Gilchrist 2012), and the sample represents both visitors to the hospital of St. Mary and the local inhabitants of London (Connell et al. 2012). The population from the York Barbican cemetery would have lived on the fringes of medieval York (McIntyre and Bruce 2010). This was a community became increasingly poor when part of their parish of Fishergate was walled off in the $14^{\text {th }}$ century (Palliser 2014).

The Greek physician Hippocrates is thought to have been the first to describe physeal fractures. When discussing dislocations of the hand and foot he refers to the 'epiphysis' and how it may be displaced (Withington 1927), but as he does not expand on what this term means, it is unknown whether it refers to the anatomical construct that is defined as an epiphysis today, or something else. Medieval scholars did not seem to be aware of the physeal fracture as a concept, with the first detailed descriptions of this injury emerging in the $19^{\text {th }}$ century (Peterson 2007). However, medieval medical literature describes the treatment of dislocations and how reduction may be performed at different locations (Joubert 1578). As a displaced physeal fracture outwardly resembles a dislocation (DeLee et al. 1980), treatment consisting of reduction, immobilisation and pain relief could have been sufficient to prevent complications in many cases.

\section{METHODS}

\section{Age Assessment}

Non-adults were aged using the development of the deciduous and permanent teeth (Moorrees et al. 1963a; b) to provide both a mean age in years and age range. Individuals were excluded from the study when the third molar root was completely formed (A1/2 or Ac). Where teeth were not present, diaphyseal lengths (Maresh 1970) were measured to calculate age. In modern samples, adolescents are still susceptible to physeal fractures prior to, or even during epiphyseal fusion (Peterson et al. 1994). Individuals with long bone epiphyses fused were excluded, with the exception of individuals with either (1) fused distal humeral epiphyses and/or (2) fused proximal radial epiphyses, as both can occur relatively early (Scheuer and Black 2004). In calculation of true prevalence rates, these fused locations were excluded, which enabled the study of unfused long bones in older adolescents.

Four broad age categories were employed to reflect potential differences in child development and activities in the medieval period. Infancy (0-1 year) is defined as a time when the child is immobile and thus unlikely to be affected by accidental skeletal injury; early childhood (1-6 years), a time of greater mobility, exploration and independence, but still little responsibility; late childhood (7-11 years), culturally a transitional phase, where medieval 
children were entrusted with tasks and taught skills useful for later life, and activities became more gendered. During adolescence (12-17 years), medieval children would have been able to move away from home to become servants or apprentices, taking on more adult occupations (Goldberg 2006; Goldberg 2008; Gilchrist 2012).

\section{Trauma assessment: macroscopic}

Assessment consisted of close observation of all long bone metaphyses for pathological changes consistent with the fracture types and complications outlined by Salter and Harris (1963). A summary of these traits is provided in Table 3. A comparison with the unaffected side was found to be the most affective aid in the identification of abnormalities. Clinical data indicates hand and feet are often affected in modern samples (Peterson et al. 1994), consequently all surviving metacarpals, metatarsals and associated phalanges were also studied.

\section{Trauma assessment: Radiographic}

Digital radiographs using both anteroposterior and mediolateral views were used to further explore features which were difficult to interpret based on macroscopic appearance alone. When the metaphysis or epiphysis is involved in the injury, displacement of these fragments can be seen macroscopically, while healing can be identified radiographically from fracture lines or sclerosis (Ogden 2000; Beaty and Kasser 2006; Johnson et al. 2009). In

Table 3 some cases, bone groups were examined to identify potentially associated trauma. This especially applies to the bones of the elbow, where physeal and other fractures can occur together (John et al. 1996). Radiography was also used to distinguish between 'normal' and 'abnormal' epiphyseal fusion. Growth arrest was inferred by the identification of a sclerotic bone bridge (Ogden 2000, 213-214).

\section{RESULTS}

A total of 12 physeal fractures were identified (12/961, CPR $1.2 \%)$. A list of all cases with location affected, traits identified and age category is given in Table 4 along with a summary description and interpretation. Cases are labelled with the original skeleton number with abbreviations to denote the sample site ( $\mathrm{SP}=\mathrm{St}$. Mary Spital, BA= Barton-upon-Humber, RA=Raunds Furnells and SOP $=$ St. Oswalds Priory). Of these 12, 10 cases (83\%) were identified through the presence of secondary complications and the remaining two cases $(17 \%)$ were identified because the lesion had not completely healed. The majority of lesions were found at the distal end of the bone (75\% or 9/12). Most commonly affected was the distal humerus (n=3) (Fig. 3). In a modern sample of 951 physeal fractures, this location is listed as the seventh most commonly affected (Peterson et al. 1994). Due to the amount of elements examined, the overall true prevalence rate was extremely low $(0.05 \%)$. This number is also low when calculated separately within each age category $(0-1$ years: $0.05 \%$; $1-6$ years: $0.02 \%$; $7-12$ years: $0.02 \%)$, although it is at its highest in the $12-17$ year olds $(0.2 \%)$. In fact, the majority of physeal fractures were found in this age group $(58 \%$ or $7 / 12)$, with the highest number of fractures at the ankle (distal tibia and fibula combined $n=3$ ), followed by the foot phalanges $(n=2)$.

\section{DISCUSSION \\ Application of methods}

This section outlines the types of lesions identified in reference to specific case studies. In general, it was easier to identify injuries when more than one type of lesion presented. The broad definition of physeal fractures allowed for a number of different lesions to be identified, and these are illustrated in Figure 4. It was possible to identify fragmentation 
of the epiphysis and the metaphysis, irregularities due to metaphyseal or metaphysealepiphyseal necrosis, and surface resorption. Necrosis is secondary to severe cellular disorganisation and damage to the growth plate blood supply (Ogden 2000). Metaphysealepiphyseal necrosis was identified in two cases, one in a fifth metacarpal of a 5-6 year old. The affected bone has a smooth, depressed distal surface, marked by a central lesion that has breached the cortex and has healed margins (Fig. 5a). To compare, a normal metaphyseal surface at the same location displays an irregular, flat surface (Fig. 5b). On radiograph the central depression is sclerotic and has a layered appearance, and is also distinct from other metacarpals of the same hand (Fig. 5c). Central growth arrest and necrosis of the epiphysis is a likely interpretation.

Localized metaphyseal angulation with metaphyseal 'cloaking' or subperiosteal new bone formation was identified in two children (Table 4), demonstrating the usefulness of the 'metaphyseal SNBF' trait (Fig 4e) as an indicator of periosteal tearing secondary to epiphyseal displacement. One case was a distal humerus of a 0-3 month-old infant from St Oswald's Priory. The lateral condyle was abnormally broad, and what remained of the metaphysis indicated a varus angulation, while the olecranon fossa displayed an irregular shape (Fig. 6). In mediolateral view, the humerus shows posterior displacement as evidenced by the abnormal depth of the coronoid fossa (Fig. 6a). In addition to these changes, the entire posterior metaphysis was cloaked in subperiosteal new bone formation (Fig. 6b). The metaphyseal changes and new bone formation could have been caused by a posterior displacement of the cartilaginous epiphysis (DeLee et al. 1980).

Partial growth arrest without necrosis (Fig $4 \mathrm{f}$ ) was observed in the proximal radius of a child aged 8-9 years old from London, resulting in angulation of the joint surface (Fig. 7a). This was confirmed by radiographic examination, in which partial growth arrest could be identified (Fig. 7b).

In two cases, the specimens were identified based on traits other than within the predicted terminology, both were identified at the distal humerus (Table 4). One case consisted of non-union of after a displaced lateral condyle fracture (BA 230), while another child aged 10-12 years demonstrated a humerus with a reduced epicondylar process in comparison to the right side (Fig. 8a). On radiograph the cortex had lost its usual morphology and had a clearly defined radio-opaque margin (Fig. 8b). This is consistent with non-union of the epicondyle after avulsion (Farsetti et al. 2001).

\section{Age-specific trends}

The true prevalence rate of physeal injuries increased with age in the current sample, and was at its highest in the 12-17 year olds $(0.2 \%)$. While this may reflect the modern age pattern for this injury (Peterson et al. 1994; Caine et al. 2006), similar cases in younger individuals may have been missed due to a lack of complications or subsequent healing. As remodelling is more efficient in younger children (<10 years) (Gasco and de Pablos 1997), it follows that more injuries in these age categories would be missed and so interpretations based on age patterning should be treated with caution. However, this study did demonstrate the presence of physeal fractures and deformities in children from all age groups, highlighting the applicability of the developed criteria.

Each identified injury has the potential to convey information about the child, their treatment and activities by ascertaining the fracture mechanism and magnitude of force which caused the lesion. These factors may be determined by the age of the child and their biosocially determined role in society. For example, the healing physeal fracture of the distal humerus recorded in the infant from St Oswald's Priory is unlikely to have been caused as a direct result of the child's movements, as they would have been wholly dependent on adults at this age. Instead, the epiphyseal displacement was most likely caused by twisting of the arm 
during childbirth; as it is often linked to difficult deliveries (Beaty and Kasser 2006; Jacobsen et al. 2009). As in young infants the bone is very responsive, healing may be visible on radiograph in under two months (Jacobsen et al. 2009), which also fits with this child's age (estimated 0-3 months). This seems to suggest that in this case the delivery in question was difficult but successful, perhaps providing a clue to the wealth of knowledge and experience of the village midwives during this period (Goldberg 2006).

Another lesion identified in a young child (SP 18339, 1.5-2.5 years) from London indicates a severe injury. Physeal injuries of the distal femur are uncommon (Peterson et al. 1994), and usually caused by a high magnitude of force (Craig et al. 1999; Ogden 2000). This physeal fracture was found in the left femur, and was associated with three other non-physeal fractures that affected the diaphyses of the right radius and ulna, and the right femur. This may indicate the child was the victim of an accident, involving either a fall from a considerable height or perhaps a horse and cart (Towner and Towner 2000), although physical abuse is also a possibility (Worlock and Stower 1986; Carty 1993).

The majority of these physeal injuries, however, were likely due to accidental causes. In the 1-6 year age category, the physeal fracture of the $5^{\text {th }}$ metacarpal suggests a fall, with the child striking a surface with a clenched fist (Lee et al. 2004). In the 7-11 year age category, physeal fractures affecting the distal humerus and proximal radius suggest falls on an outstretched hand, with the force of the impact transmitted to the elbow (John et al. 1997). Children of this age would have been doing tasks and learning new skills, but simultaneously sources suggest they still got injured while playing (Hanawalt 1977; 1986). The ambiguity of the transition is illustrated by contemporary writings, in which children are said to learn 'good and bad habits', as well as 'desiring... those things that are harmful and contrary'

(MacLehose 2008, p. 29); this seems to suggest an awareness of the lasting 'childishness' as well as a capacity for learning attributed to this age.

In adolescence (12-17 years), such falls still occur, as evidenced by a physeal fracture of the distal humerus and one affecting the distal radius. A direct impact to the epiphysis leading to a non-displaced Salter-Harris III injury is a likely cause of the latter. This makes falls on an outstretched hand the most common aetiology in the entire sample (4/12 or 33\%). More severe, perhaps, were the injuries of the distal tibia $(n=2)$, which suggest accidents leading to twisting of the ankle (Ogden 2000). The presence of complications suggests a high magnitude of force (Ogden 2000; Leary et al. 2009). Both cases are from London. It is possible that these were sustained during work accidents, such as falls from scaffolding. Sources indicate construction work was hazardous for both young and old, and could have involved apprentices (Metzler 2013).

\section{Challenges to the study of non-adult trauma}

A large number of physeal injuries will only ever be identified through the presence of secondary complications, a fact which presents us with problems at the level of interpretation. Most clinical examples involve treatment that prevents observations into the natural progression of the complication and its subsequent appearance. While the study of non-adults allows for a more accurate assessment of the age at which injuries occur, several cases in this study were healing and almost certainly happened when the child was younger. In these cases it will never be possible to gauge the exact timing of the trauma. In any event recording the age of the individual displaying trauma of a certain type and location should be recorded to help us build up a picture of childhood injuries in the past.

True prevalence rates should always be calculated to take into account issues of recovery of the smallest bones, such as the phalanges of the hands and feet, a particular challenge when excavating non-adults. These are common sites of injury in modern children, however, they are associated mainly with sports, activities that are almost exclusively modern 
(Peterson et al. 1994). This, combined with few complications in this location, might account for their absence from this osteological sample.

Another challenge is differentiating between conditions that may cause similar changes in the skeleton. For example, differential diagnoses for metaphyseal 'cupping' should include other pathological conditions involving the growth plate such as achondroplasia, sickle-cell anaemia, hypervitamintosis A, tuberculosis and acute osteomyelitis. However, such cases are usually bilateral or multifocal (Caffey 1970). This allows for differential diagnosis if the skeleton is well-preserved. Metaphyseal cupping has also been linked to trauma involving the soft tissues, such as burns, frostbite and insertion of metal (Ogden 2000), although these injuries are usually confined to the hand.

\section{CONCLUSIONS}

This study demonstrated the potential for the identification of physeal fractures in nonadult skeletons of all ages. Identification criteria need to be created in relation to the principles of paediatric bone and its reaction to trauma, common childhood fracture types, their epidemiology and their complications. While the number of indiyiduals identified with physeal fractures was small at $1.2 \%$, each injury has the potential to reveal information about the circumstances of the injury at different stages of the medieval life course. In the present study, a high number of falls at all ages, and birth injuries were indicated by physeal injuries. These also increased with age and were more common on the distal end of the bone. Although injuries that resulted in a series of abnormalities were easier to identify macroscopically, this study also illustrated that it was possible to recognise trauma that occurred without deformity. It also highlights the importance of radiographs in understanding the nature and extent of healing.

\section{ACKNOWLEDGEMENTS}

This project was funded by a research studentship under the Leverhulme Trust funded project: "Adolescence, Migration and Health in Medieval England". The authors thank Dr. Simon Mays and Kevin Booth (English Heritage) for permitting and facilitating access to the Bartonupon-Humber collection. We also gratefully acknowledge Dr. Jo Buckberry and Dr. Emma Brown (University of Bradford) and Dr. Pia Nystrom and Dr. Diana Swales (University of Sheffield), for access to collections and assistance with radiography. Lastly, the authors thank Dr. Rebecca Redfern and Jelena Bekvalec (CHB, Museum of London) for access to the Mary Spital material, and Wayne Hoban and Mark Viner (Reveal Imaging) for their help with and expertise on radiographic imaging while in London.

\section{LITERATURE CITED}

Audouy M, and Chapman A, editors. 2009. Raunds. The Origin and Growth of a Midland Village AD 450-1500. Excavations in north Raunds, Northamptonshire 1977-87. Oxford: Oxbow Books.

Baker N, and Holt R. 2004. Urban Growth and the Medieval Church. Aldershot: Ashgate.

Basener CJ, Mehlman CT, and DiPasquale T. 2009. Growth disturbance after distal femoral growth plate fractures in children: a meta-analysis. J Orthop Trauma 23(9):663-667.

Beaty J, and Kasser J, editors. 2006. Rockwood and Wilkins' Fractures in Children. Sixth Edition ed. Philadelphia: Lippencott Williams and Wilkins.

Boddington A. 1996. Raunds Furnells: the Anglo-Saxon Church and Churchyard. London: English Heritage Archaeol Rep. 
Brashear HR. 1959. Epiphyseal fractures. A microscopic study of the healing process in rats. J Bone and Joint Surg A 41(6):1055-1076.

Bryant GF. 2003. The Church in Late Medieval Barton-on-Humber. The Later History of Barton-on-Humber: Part I. WEA, Barton-on-Humber: Privately Printed.

Caffey J. 1970. Traumatic cupping of the metaphysis of growing bones. Am J Roentgenol 108(3):451-460.

Caine D, Difiori J, and Maffulli N. 2006. Physeal injuries in children's and youth sports: reasons for concern? Br J Sports Med 40:749-760.

Cannata G, De Maio F, Mancini F, and Ippolito E. 2003. Physeal Fractures of the Distal Radius and Ulna: Long-Term Prognosis. J Orthop Trauma 17(3):172-179.

Carty H. 1993. Fractures caused by child abuse. J Bone and Joint Surg Br 75(6):849-857.

Centre for Human Bioarchaeology. 2013a. St. Mary Spital (SRP98) period 14 workbook. Museum of London.

Centre for Human Bioarchaeology. 2013b. St. Mary Spital (SRP98) period 15 workbook. Museum of London.

Centre for Human Bioarchaeology. 2013c. St. Mary Spital (SRP98) period 16 workbook. Museum of London.

Centre for Human Bioarchaeology. 2013d. St. Mary Spital (SRP98) period 17 workbook. Museum of London.

Connell B, Jones A, Redfern R, and Walker D. 2012. A Bioarchaeological Study of Medieval Burials on the Site of St. Mary Spital. London: Museum of London Archaeology.

Craig JG, Cramer KE, Cody DD, Hearshen DO, Ceulemans RY, van Holsbeeck MT, and Eyler WR. 1999. Premature partial closure and other deformities of the growth plate: MR imaging and three-dimensional modeling. Radiology 210(3):835-843.

Dawes JD, and Magilton JR. 1980. The Cemetery of St. Helen-on-the-Walls, Aldwark. London: Council for British Archaeology for the York Archaeological Trust.

DeLee JC, Wilkins KE, Rogers LF, and Rockwood CA. 1980. Fracture-separation of the distal humeral epiphysis. J Bone Joint Surg Am 62(1):46-51.

Djuric MP, Janovic A, Milovanovic P, Djukic K, Milenkovic P, Draskovic M, and Roksandic M. 2010. Adolescent health in medieval Serbia: signs of infectious diseases and risk of trauma. Homo - Journal of Comparative Human Biology 61:130-149.

Eastwood DM, and de Geldere A. 2011. Physeal injuries in children. Surgery (Oxford) 29(4):146-152.

Ecklund K, and Jaramillo D. 2002. Patterns of premature physeal arrest: MR imaging of 111 children. AJR Am J Roentgenol 178(4):967-972.

Farsetti P, Potenza V, Caterini R, and Ippolito E. 2001. Long-term results of treatment of fractures of the medial humeral epicondyle in children. J Bone Joint Surg Am 83A(9):1299-1305.

Fibiger L. 2013. Misplaced childhood? Interpersonal violence and children in Neolithic Europe. In: Knusel C, and Smith M, editors. The Routledge Handbook of the Bioarchaeology of Human Conflict. Abingdon-New York: Routledge. 
Flynn JC, and Richards JF, Jr. 1971. Non-union of minimally displaced fractures of the lateral condyle of the humerus in children. J Bone Joint Surg Am 53(6):1096-1101.

Flynn JC, Richards JF, Jr., and Saltzman RI. 1975. Prevention and treatment of non-union of slightly displaced fractures of the lateral humeral condyle in children. An end-result study. J Bone Joint Surg Am 57(8):1087-1092.

Gaither C, and Murphy M. 2012. Consequences of conquest? The analysis and interpretation of subadult trauma at Puruchuco-Huaquerones, Peru. J Arch Science 39:467-478.

Gasco J, and de Pablos J. 1997. Bone remodeling in malunited fractures in children. Is it reliable? J Pediatr Orthop B 6(2):126-132.

Gilchrist R. 2012. Medieval Life. Archaeology and the Life Course. Woodbrigde: Boydell Press.

Glencross B. 2011. Skeletal injury across the life course: towards understanding social agency. In: Agarwal S, and Glencross B, editors. Social Bioarchaeology. Chichester: Wiley-Blackwell. p 390-409.

Glencross B, and Stuart-Macadam P. 2000. Childhood trauma in the archaeological record. Int J Osteoarchaeol 10:198-209.

Glencross B, and Stuart-Macadam P. 2001. Radiographic clues to fractures of distal humerus. Int J Osteoarchaeol 11:298-310.

Goldberg PJP. 2006. Life and death: the ages of man. In: Horrox R, and Ormrod WM, editors. A Social History of England 1200-1500. Cambridge: Cambridge University Press. p 413-434.

Goldberg PJP. 2008. Childhood and gender in later/medieval England. Viator 39(1):249-262.

Gruber HE, Phieffer LS, and Wattenbarger JM. 2002. Physeal fractures, part II: fate of interposed periosteum in a physeal fracture. J Pediatr Orthop 22(6):710-716.

Hanawalt B. 1977. Childrearing among the lower classes of Medieval England. The Journal of Interdisciplinary History 8(1):1-22.

Hanawalt B. 1986. The ties that bound : peasant families in medieval England. New York: Oxford University Press. xii, 346 p. p.

Hardacre JA, Nahigian SH, Froimson AI, and Brown JE. 1971. Fractures of the lateral condyle of the humerus in children. J Bone Joint Surg Am 53(6):1083-1095.

Heighway C, and West J. 1980. Excavations at Gloucester, fifth interim report: St Oswalds Priory: 1977-8. The Antiquaries Journal 60:207-226.

Jacobsen S, Hansson G, and Nathorst-Westfelt J. 2009. Traumatic separation of the distal epiphysis of the humerus sustained at birth. J Bone and Joint Surg Br 91(6):797-802.

Jimenez-Brobeil SA, Al Oumaoui I, and Du Souich P. 2007. Childhood trauma in several populations from the Iberian Peninsula. Int J Osteoarchaeol 17:189-198.

John SD, Moorthy CS, and Swischuk LE. 1997. Expanding the concept of the toddler's fracture. Radiographics 17(2):367-376.

John SD, Wherry K, Swischuk LE, and Phillips WA. 1996. Improving detection of pediatric elbow fractures by understanding their mechanics. Radiographics 16(6):1443-1460; quiz 1463-1444. 
Johnson K, Williams H, Foster KE, and Miller C. 2009. Paediatric Radiology. Oxford: Oxford University Press.

Joubert L. 1578. La Grande Chirurgie de M. Guy de Chauliac. Venice: Simon Rigaud.

Leary JT, Handling M, Talerico M, Yong L, and Bowe JA. 2009. Physeal fractures of the distal tibia: predictive factors of premature physeal closure and growth arrest. J Pediatr Orthop 29(4):356-361.

Lee P, Hunter TB, and Taljanovic M. 2004. Musculoskeletal colloquialisms: how did we come up with these names? Radiographics 24(4):1009-1027.

Lewis ME. 2013. Children of the golden minster: St. Oswald's Priory and the impact of industrialisation on child health. J Anthropology Published online http://dx.doi.org/10.1155/2013/959472:1-11.

Lewis ME. 2014. Sticks and stones: the nature, prevalence and significance of trauma in the child. In: Smith M, and Knusel C, editors. The Routledge Handbook of the Bioarchaeology of Human Conflict. Abingdon-New York: Routledge. p 39-64.

MacLehose WF. 2008. "A Tender Age". Cultural Anxieties over the Child in the Twelfth and Thirteenth Centuries. New York: Columbia University Press.

Mann DC, and Rajmaira S. 1990. Distribution of physeal and nonphyseal fractures in 2,650 long-bone fractures in children aged 0-16 years. J Pediatr Orthop 10(6):713-716.

Maresh MM. 1970. Measurements from roentgenograms. In: McCammon RW, editor. Human Growth and Development. Springfield IL: C.C. Thomas. p 157-200.

Mays S, Harding C, and Heighway C, editors. 2007. The Churchyard. York: York University Press.

McIntyre L, and Bruce G. 2010. Excavating All Saint's: a Medieval church rediscovered. Current Archaeology 245:30-37.

Metzler I. 2013. A Social History of Disability in the Middle Ages. New York - London: Routledge, Taylor \&/Francis Group.

Moorrees C, Fanning E, and Hunt E. 1963a. Age variation of formation stages for ten permanent teeth. Dental Research 42(6):1490-1502.

Moorrees C, Fanning E, and Hunt E. 1963b. Formation and resorption of three deciduous teeth in children. Am J Phys Anthropol 21(2):205-213.

Ogden JA. 2000. Skeletal Injury in the Child. New-York - Berlin - Heidelberg: Springer.

Palliser DM. 2014. Medieval York 600-1540. Oxford: Oxford University Press.

Peterson CA, and Peterson HA. 1972. Analysis of the incidence of injuries to the epiphyseal growth plate. J Trauma 12(4):275-281.

Peterson HA. 2007. Epiphyseal Growth Plate Fractures. Berlin-Heidelberg: Springer.

Peterson HA, Madhok R, Benson JT, Ilstrup DM, and Melton LJ, 3rd. 1994. Physeal fractures: Part 1. Epidemiology in Olmsted County, Minnesota, 1979-1988. J Pediatr Orthop 14(4):423-430.

Rathjen K, and Birch J. 2006. Physeal injuries and growth disturbances. In: Beaty J, and Kasser J, editors. Rockwood and Wilkins' Fractures in Children. PhiladelphiaBaltimore: Lippincott Williams and Wilkins. p 99-131. 
Salter RB, and Harris WH. 1963. Injuries involving the epiphyseal plate. J Bone and Joint Surg 45:587-622.

Scheuer L, and Black S. 2004. The Juvenile Skeleton. Amsterdam - Boston - Heidelberg London: Elsevier Academic Press.

Stamper P. 2009. Rural settlements and manors. In: Hunter D, and Ralston I, editors. The Archaeology of Britain An Introduction from Earliest Times to the Twenty-First Century. London-New York: Routledge. p 328-347.

Towner E, and Towner J. 2000. Developing the history of unintentional injury: the use of coroners' records in early modern England. Inj Prev 6(2):102-105.

Waldron T, and Rodwell W. 2007. St. Peter's, Barton-upon-Humber, Lincolnshire. A Parish Church and its Community. Oxford: Oxbow Books.

Withington ET. 1927. Hippocrates (vol. III). London - New York: William Heinemann.

Worlock P, and Stower M. 1986. Fracture patterns in Nottingham children. J Pediatr Orthop 6(6):656-660.

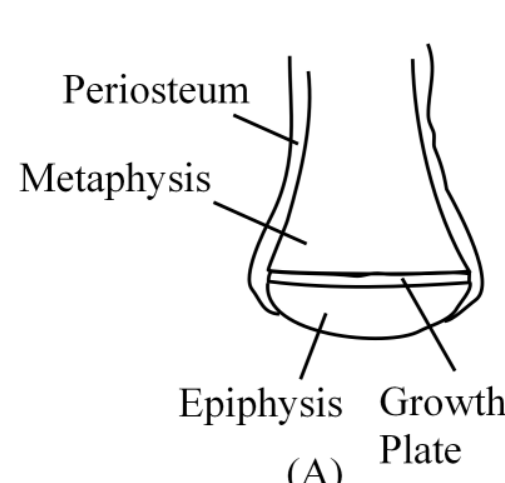

(A)

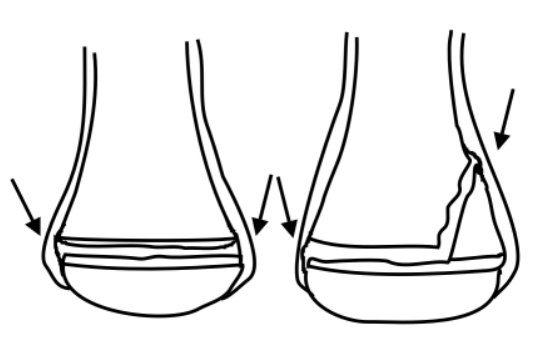

(B)

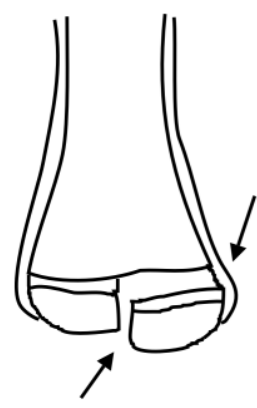

(D)

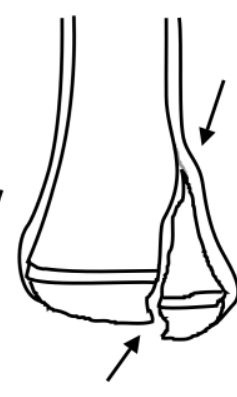

(E)

Fig. 1: Schematic drawings depicting normal bone end (a) and physeal fracture mechanisms Salter-Harris I (b), Salter-Harris II (c), Salter-Harris III (d) and Salter-Harris IV (e) fractures. Redrawn from Eastwood and de Geldere (2011)
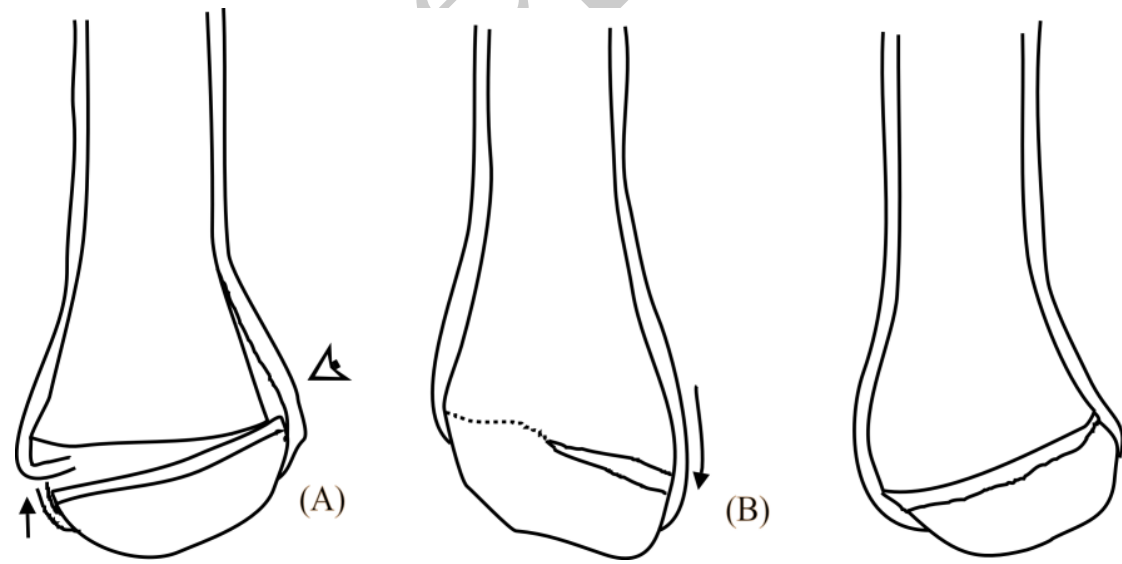

(C)

Fig. 2: Possible complications after a displaced epiphysis. (a) Displacement of the fragment can lead to tearing of the periosteum on the side of tension (arrow) and stripping of the periosteum on the side of compression (white arrow), leading to subperiosteal new bone formation. (b) After reduction, interposition of the torn periosteum may lead to peripheral 
growth arrest, with an angulation created by growth continuing on one side. (c) The displacement may become permanent if unreduced, leading to a localized angulation

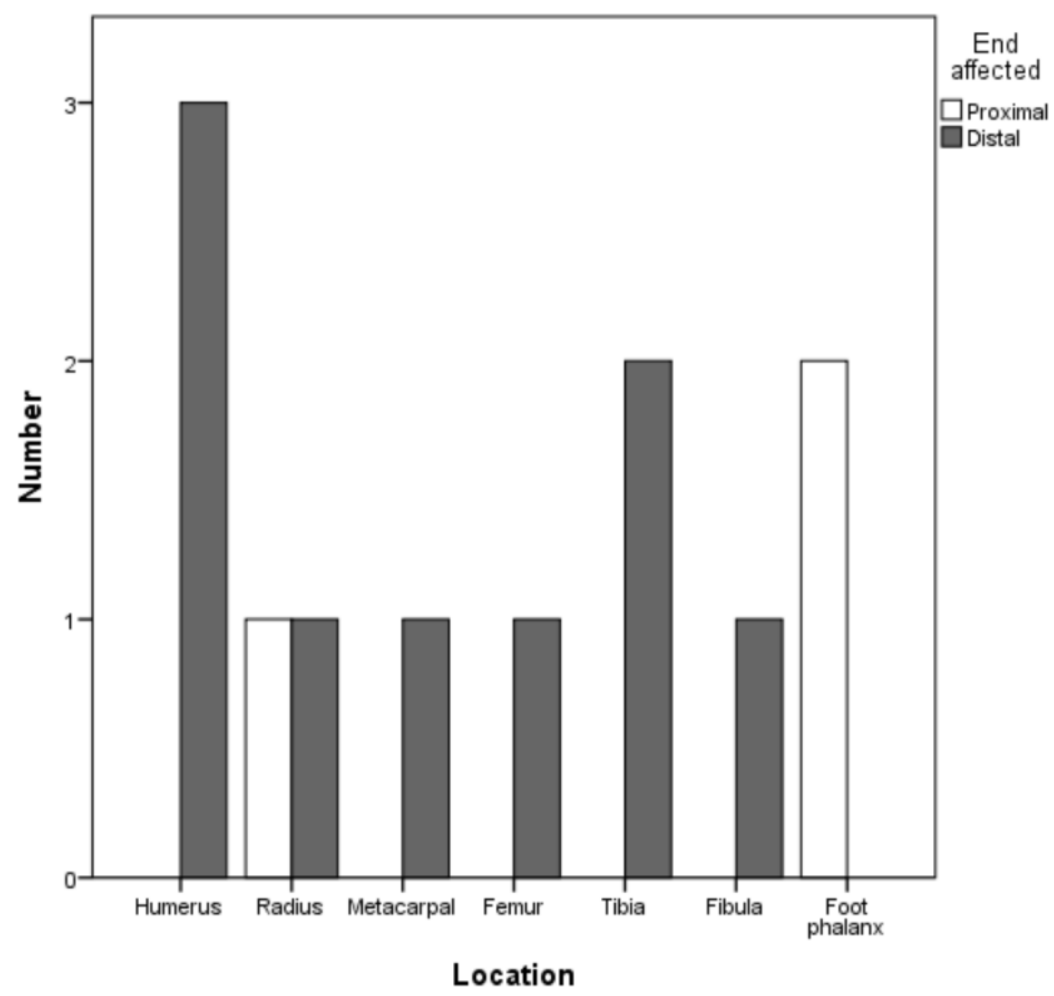

Fig. 3: Overview of affected locations and affected bone ends 


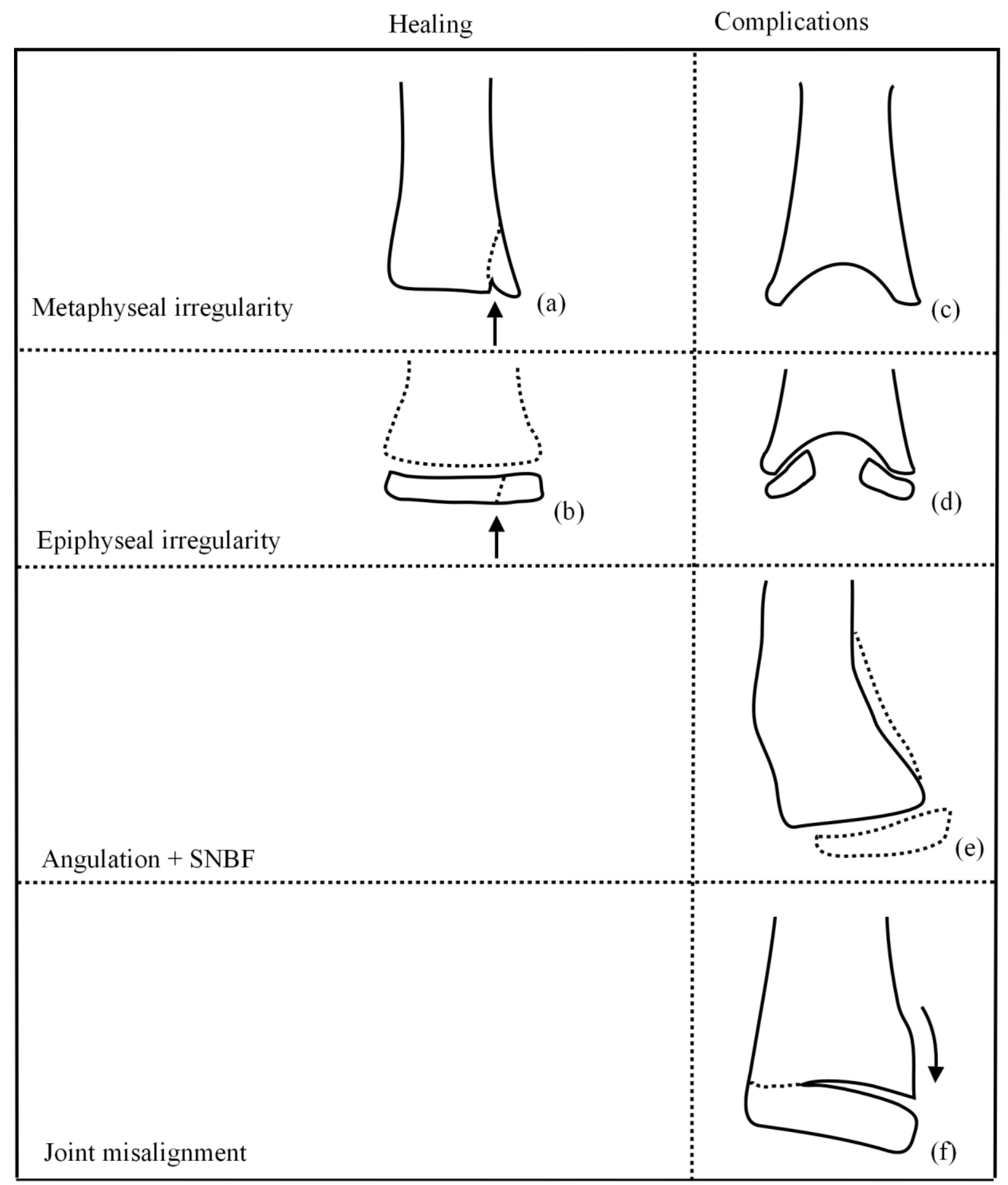

Fig. 4: Illustrated changes which can be seen in dry bone after physeal fracture 

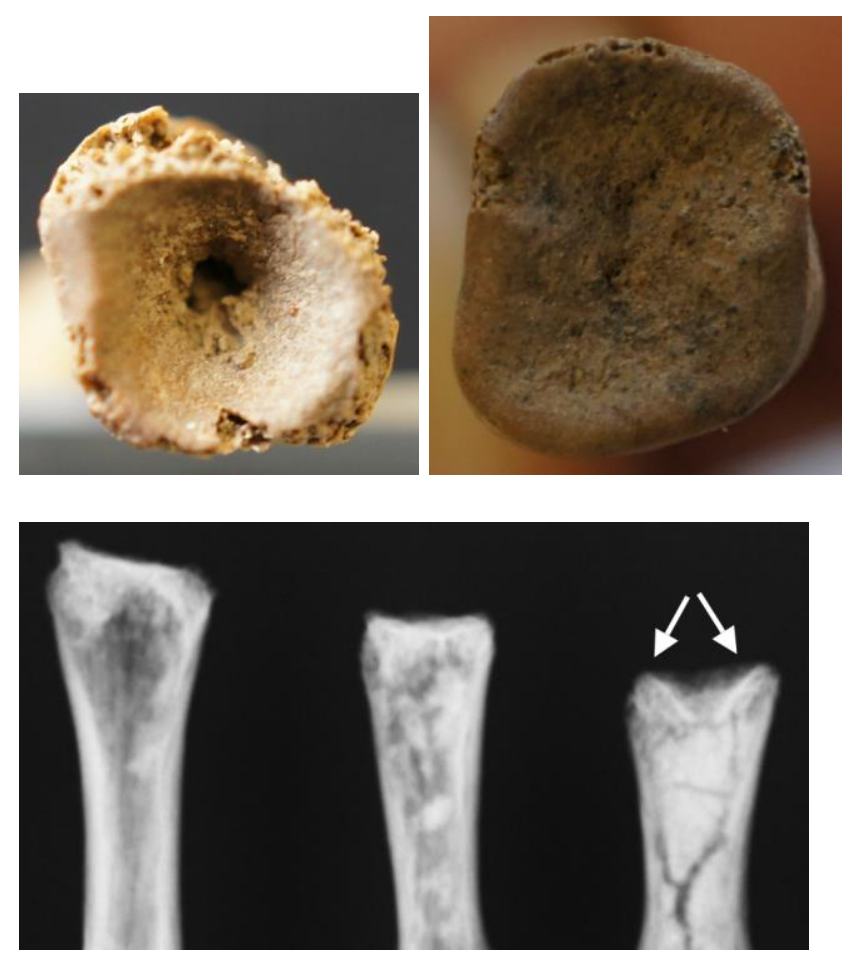

Fig. 5: Barton-upon-Humber, Sk. 2256. Compare (a) the affected 5th metacarpal (distal view) with (b) a normal specimen of similar age (mean age: 6 years). (c) On radiograph (anteroposterior view) compare normal appearance of the distal metaphysis to the abnormal appearance in the 5th metacarpal (arrowed). Images courtesy of English Heritage.

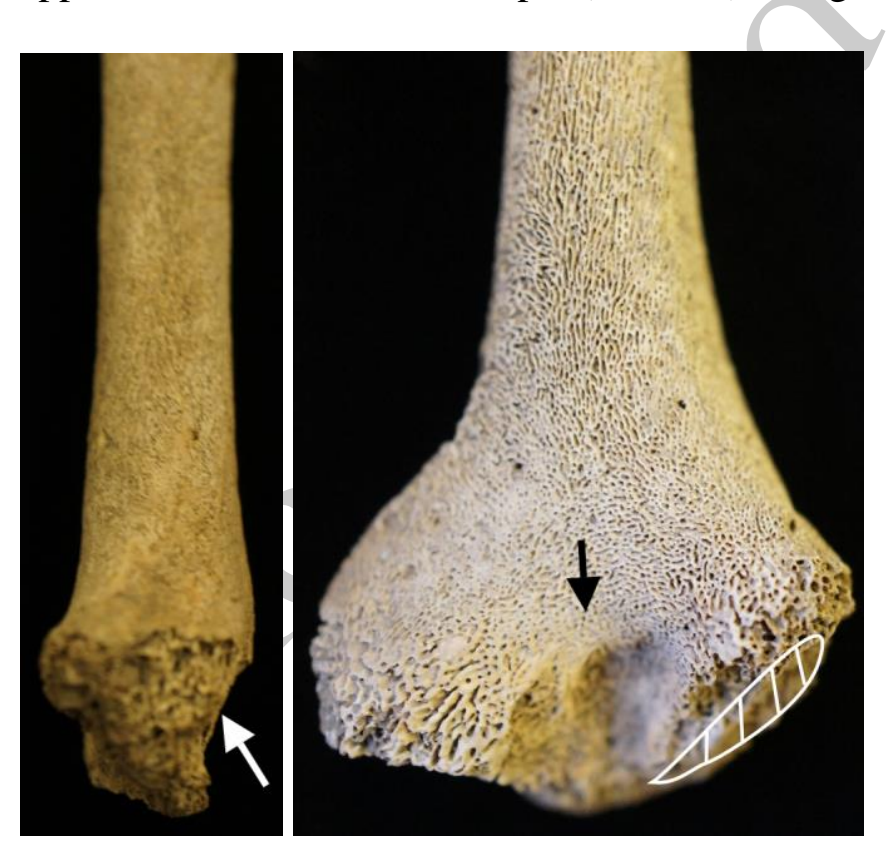

Fig. 6: St. Oswalds Priory, Sk. 13 (a) Mediolateral view, showing posterior displacement of distal humerus and enlargement of coronoid fossa (white arrow). (b) Medial tilt (arrow) can be observed in posterior view, even though the metaphyseal surface is damaged (shaded area). The irregular shape of the olecranon fossa is arrowed 

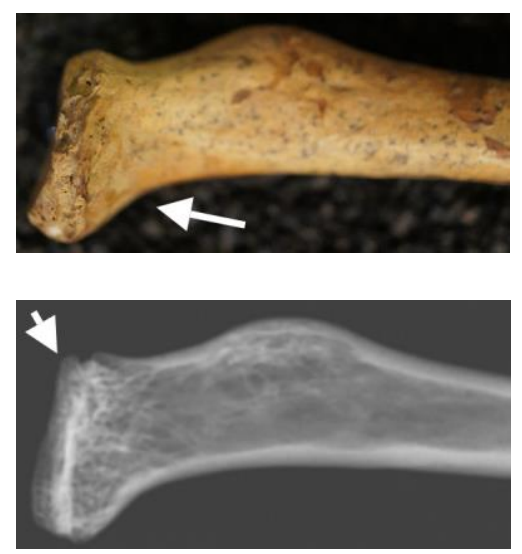

Fig. 7: St. Mary Spital, Sk. 19284 (a) mediolateral view of proximal right radius, with tilted joint surface and fused epiphysis. (b) Mediolateral radiograph - the epiphysis is still visible as a separate structure, with growth arrest taking place anteriorly (arrowed) and growth continuing posteriorly (radio-opaque line), leading to the joint angulation. Skeleton from St. Mary Spital collection, curated at the Museum of London (SRP98). Images (C) Museum of London

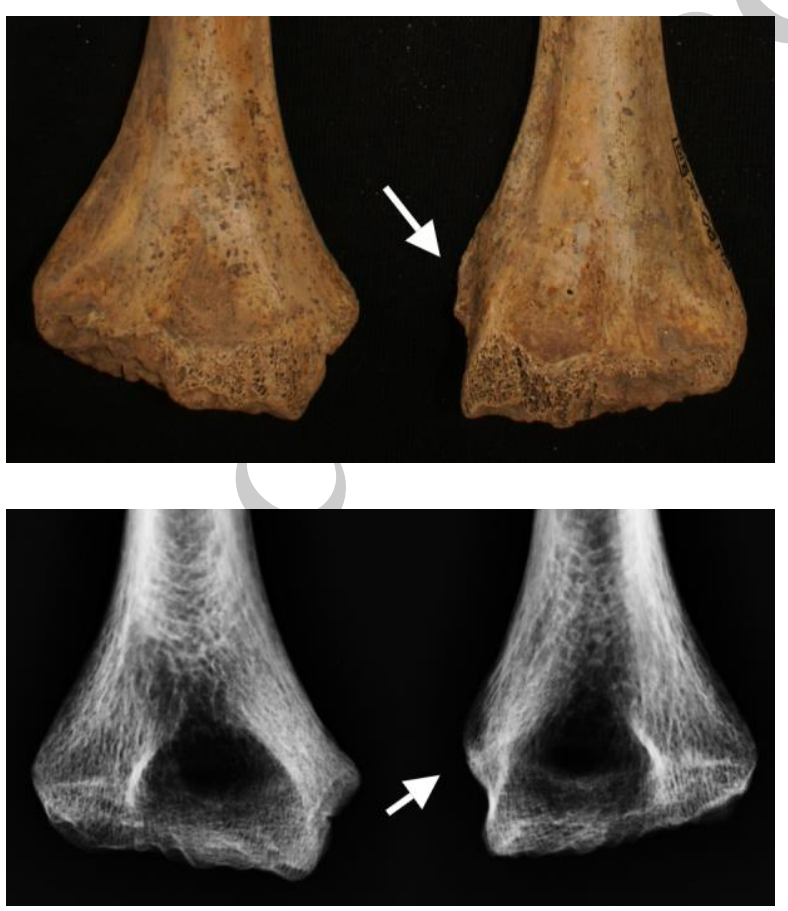

Fig. 8: Barton-upon-Humber, Sk. 318 (a) Comparative anteroposterior view of left and right humerus shows the underdevelopment of the apophyseal surface for the right medial epicondyle. (b) Radiographic examination reveals the different outline of the apophyseal surfaces - the normal, diffuse outline of the growth plate has been replaced by a more radioopaque margin. Images courtesy of English Heritage. 
Table 1: List of growth arrest prevalence from modern clinical studies ${ }^{\mathbf{a}}$

\begin{tabular}{lll}
\hline Location & Growth arrest $(\mathrm{n} / \mathrm{N})^{*}$ & Growth arrest $(\%)$ \\
\hline Distal radius & $7 / 157$ & 4.4 \\
Hand phalanx & $17 / 1377$ & 1.2 \\
Distal femur & $291 / 564$ & 51.5 \\
Distal tibia & $15 / 124$ & 12.1
\end{tabular}

$*_{\mathrm{n}}=$ number affected, $\mathrm{N}=$ number observed

${ }^{a}$ Data summarized from Basener et al. (2009), Cannata et al.

(2003), Leary et al. (2009) and Peterson (2007)

Table 2: Study Sites.

\begin{tabular}{lllll}
\hline Site name & $\mathrm{n}$ & Context & Date & Reference \\
\hline Barton-upon Humber, Lincolnshire & 370 & Semi-urban & AD 950-1500 & Waldron (2007) \\
Raunds Furnells, Northamptonshire & 129 & Rural & AD 900-1100 & Boddington (1996) \\
St. Mary Spital, London & 285 & Urban & AD 1120-1539 & Connell ct al. (2012) \\
St. Oswald's Priory, Gloucester & 83 & Rural & AD 900-1540 & Lewis (2013) \\
York Barbican & 94 & Urban & AD 1000-1600 & McIntyre and Bruce (2010) \\
\hline Total & $\mathbf{9 6 1}$ & & & \\
\hline
\end{tabular}

Table 3: List of traits relevant to the identification of physeal fractures

\begin{tabular}{|c|c|c|c|}
\hline Trait & Indicates & Cause & Reference \\
\hline Metaphyseal SNBF* & Localized periosteal tearing & Epiphyseal displacement & Brashear (1959) \\
\hline Metaphyseal irregularity & Fragmented metaphysis & Salter-Harris II & Eastwood (2011) \\
\hline Epiphyseal irregularity & Fragmented epiphysis & Salter-Harris III & Eastwood (2011) \\
\hline \multirow[t]{2}{*}{ Localized angulation } & Peripheral growth arrest & All & Ogden (2000) \\
\hline & Displaced epiphysis & All & Peterson (2007) \\
\hline Joint misaligment & Central/peripheral growth & Salter-Harris III, IV & Ecklund (2002) \\
\hline Length discrepancy & $\begin{array}{l}\text { Central/complete growth } \\
\text { arrest }\end{array}$ & Salter-Harris III, IV & Ecklund (2002) \\
\hline
\end{tabular}

* Subperiosteal new bone formation

Table 4: List of specimens identified in this study and summary of observations

\begin{tabular}{|c|c|c|c|c|c|}
\hline SK no. & Location & Main trait(s) & $\begin{array}{l}\text { Age cat. } \\
\text { (years) }\end{array}$ & Ill. $^{\mathrm{a}}$ & Interpretation \\
\hline SP 23981 & Distal tibia & Metaphyseal irregularity & $12-17$ & $4 \mathrm{a}$ & $\begin{array}{l}\text { Metaphyseal fragmentation } \\
\text { (Triangular fragment) }\end{array}$ \\
\hline SP 1405 & Distal radius & Epiphyseal irregularity & $12-17$ & $4 \mathrm{~b}$ & Epiphyseal fragmentation \\
\hline SP 18339 & Distal femur & Angulation \& & $1-6$ & $4 \mathrm{e}$ & Displaced epiphysis \\
\hline
\end{tabular}




\begin{tabular}{|c|c|c|c|c|c|}
\hline SP 19163 & Foot phalanx & Metaphyseal irregularity & $12-17$ & $4 c$ & Partial metaphyseal necrosis \\
\hline SP 19274 & $\begin{array}{l}\text { Proximal } \\
\text { radius }\end{array}$ & Joint misalignment & $7-11$ & $4 \mathrm{f}$ & Peripheral growth arrest \\
\hline SP 29075 & Distal tibia & $\begin{array}{l}\text { Metaphyseal \& } \\
\text { epiphyseal irregularity }\end{array}$ & $12-17$ & $4 d$ & $\begin{array}{l}\text { Metaphyseal-epiphyseal } \\
\text { necrosis }\end{array}$ \\
\hline BA 2256 & $5^{\text {th }}$ metacarpal & $\begin{array}{l}\text { Epiphyseal irregularity \& } \\
\text { length discrepancy }\end{array}$ & $1-6$ & $4 d$ & $\begin{array}{l}\text { Central growth arrest with } \\
\text { epiphyseal necrosis }\end{array}$ \\
\hline RA 5168 & Distal fibula & Metaphyseal irregularity & $12-17$ & $4 \mathrm{a}$ & $\begin{array}{l}\text { Metaphyseal fragmentation } \\
\text { (Triangular fragment) }\end{array}$ \\
\hline RA 5324 & Foot phalanx & Metaphyseal irregularity & $12-17$ & $4 \mathrm{c}$ & Metaphyseal necrosis \\
\hline SOP 13 & Distal humerus & $\begin{array}{l}\text { Angulation \& } \\
\text { metaphyseal SNBF }\end{array}$ & $0-1$ & $4 \mathrm{e}$ & Displaced epiphysis \\
\hline BA 230 & Distal humerus & N/A & $12-17$ & & Non-union \\
\hline BA 318 & Distal humerus & N/A & $7-11$ & & Non-union \\
\hline
\end{tabular}

${ }^{a}$ Refers to Fig. 4 in the discussion

*SNBF $=$ subperiosteal new bone formation 